\title{
Inflammatory Bowel Disease: Anatomical and Histopathological Study
}

\author{
Ahmed M. S. Hegazy', Mohammed M. Mosaed², Taha M. M. Hassan ${ }^{3}$ \\ ${ }^{1}$ Anatomy Department, Benha Faculty of Medicine, Benha University, Benha City, Egypt \\ ${ }^{2}$ Anatomy Department, Al-azhar Faculty of Medicine, Al-azhar University, Assuit City, Egypt \\ ${ }^{3}$ Pathology Department, Bani-Sowif University, Bani-Sowif City, Egypt
}

Email address:

Ahmed0562301954@yahoo.com (A. M. S. Hegazy)

\section{To cite this article:}

Ahmed M. S. Hegazy, Mohammed M. Mosaed, Taha M. M. Hassan. Inflammatory Bowel Disease: Anatomical and Histopathological Study. International Journal of Clinical and Developmental Anatomy. Vol. 1, No. 1, 2015, pp. 1-7. doi: 10.11648/j.ijcda.20150101.11

\begin{abstract}
Worldwide, the frequency of chronic inflammatory bowel disease (CIBD), including ulcerative colitis (UC) and Crohn's disease (CD) increased rapidly through the last century making their histopathological diagnosis daily task for all pathologists. The accurate histopathological diagnosis of UC and CD requires an intimate correlations between the clinical, laboratory and endoscopic findings in conjunction to the suitable obtained biopsy material, as there are several diagnostic confusions between CIBD and non CIBD forms. The aim of this study was to focus and analyze certain practically selected histopathological features for the diagnosis of UC and CD including crypt architectural abnormalities, inflammation and an associated dysplasia or adenocarcinoma. This present study was performed on 100 specimens of tissue samples taken from small and large bowel including 3 ileocecal resections which were done for suspected an IBD. All the tissue samples received fixed in $10 \%$ neutral buffered formalin fixative solution, and paraffin-embedded tissue sections were prepared and examined microscopically for the histopathological features which distinguishing CIBD from non CIBD colitis. This study revealed 95 cases CIBD, among them 55 cases CD and 40 cases were UC, whereas the remaining 5 cases were non CIBD colitis. This study concluded that the diagnosis of IBD needs interdepartmental correlations to avoid under- or over-diagnosis. As well as the accurate discrimination of CIBD from non CIBD forms, differentiate UC from CD, and to identify any dysplastic lesions which is the backbone for therapeutic and prognostic strategies.
\end{abstract}

Keywords: IBD, UC, CD, Anatomical, and Histopathological

\section{Introduction}

The gastrointestinal tract (GIT) is responsible for digestion of food, absorption of nutrients, and elimination of wastes. Inflammation impairs the ability of gastrointestinal organs to function properly. The frequency of inflammatory bowel disease (IBD), including ulcerative colitis (UC) and Crohn's disease $(\mathrm{CD})$ increased rapidly through the last century $[1,2]$ However, tends to be at the uppermost limit in developed countries [3].

Ulcerative colitis (UC) and CD are CIBD of unknown cause. Clinically, both conditions usually begin gradually, but they can start abruptly and sometimes even present as fulminant disease. UC primarily affects the mucosa of the large bowel, while $\mathrm{CD}$ is a transmural disease that can affect the whole GIT $[4,5]$.

The histopathological diagnosis of CIBD is critically important in determining the choice of treatment, the prognosis and the follow-up. The aim of the diagnosis is to; differentiate CIBD from other non CIBD colitis, differentiate $\mathrm{UC}$ from $\mathrm{CD}$, and to identify any dysplastic lesions. In addition to the above, diagnosis of IBD is a complex procedure [6]. The microscopic picture of $\mathrm{UC}$ and $\mathrm{CD}$ is often composed of basic lesions that can also be observed in other diseases and only rarely appears to be pathognomonic [7].

The causes of IBD remain unknown. There is a genetic predisposition which increases the risk of IBD about tenfold in first degree relatives of someone with IBD and which may determine the pattern and severity of the conditions in any individual patient [8]. Numerous genes and genetic mutations connected to IBD have been identified. The first one discovered was a mutation in the NOD2/CARD15 gene, which was found to be associated with developing CD [9].

There is an established link between IBD and an increased risk of developing cancer, primarily in the colon. The risk of 
colorectal cancer increases with the extent of disease, severity of inflammation, the age of onset and duration of the disease [10]. Dysplasia is the earliest histological derangements in the intestinal epithelium, and colorectal cancer in association with IBD is linked to inflammationdysplasia-cancer sequence in the GIT, which is unique pathway and unrelated to the adenoma-cancer-sequence [11].

This study aimed to provide clinical, anatomical and histopathological data helping in accurate discrimination of CIBD from non CIBD forms and differentiate UC from CD.

\section{Patients and Methods}

The present study was performed on tissue sections specimens of 100 patients. Among them 3 cases were ileocecal resections, whereas majority of the received specimens were biopsies which obtained from the large and small bowel. These biopsies were obtained endoscopically in the surgical endoscopic unit in patients who were suspected clinically and radiographically to have IBD forms of colitis. The study was conducted in the Department of Pathology, Central Hospital, Arar City, Saudi Arabia, through the period from 2010 to September 2014. The Pathology Department received surgical specimens came from 6 Central Hospitals in the Northern Region; KSA including more than 1000 beds. All the clinicoendoscopical data of the patients including age, gender, and clinical complaints were obtained from patient's medical records. All the surgical specimens were received fixed in $10 \%$ neutral buffered formalin solution, then processed and paraffin-embedded blocks were prepared, and were cut into 3 micron-thick tissue sections. These sections were stained by routine Hematoxylin and Eosin stains, and then examined microscopically. All the cases were assessed pathologically for IBD forms according to published mentioned criteria, yet certain selected histopathological features were chosen for diagnosis and evaluation. These features can be recognized by the surgical pathologists in the daily practice may be also combined together in many cases. These features represented by architectural abnormalities including crypt branching / shortening / decreased density, and mucosal-epithelial changes including intact mucosa, erosions, ulcerations, and inflammatory features which were including transmural inflammations, neutrophils in crypt epithelia (cryptitis), neutrophils in crypt lumina (crypt abscess), and epithelioid granulomas (Table 1) [7, 12, 13].

Table 1. Summarized selected histopathological features applied in the diagnosis of obtained specimens from all studied cases.

\begin{tabular}{|c|c|c|c|c|}
\hline & $\begin{array}{l}\text { * Crypt architectural abnormalities (crypt } \\
\text { distortion) }\end{array}$ & *Epithelial-mucosal changes & *Inflammatory features & $\begin{array}{l}\text { *Associated dysplasia / } \\
\text { carcinoma }\end{array}$ \\
\hline 1 & $\begin{array}{l}\text { Branching } \\
\text { ( irregular crypts with dilation) }\end{array}$ & Intact mucosa & Transmural inflammation & \\
\hline 2 & $\begin{array}{l}\text { Shortening } \\
\text { ( increasing distance between the bottom of crypts } \\
\text { and the muscularis mucosae) }\end{array}$ & $\begin{array}{l}\text { Erosions (small loss of surface } \\
\text { epithelia with mild } \\
\text { inflammation). }\end{array}$ & Cryptitis & \\
\hline 3 & Decreased density (reduction in numbers of crypts). & Ulcerations (superficial or deep). & Crypt abscess & \\
\hline 4 & Branching with decreased density & $\begin{array}{l}\text { Mucin depletion (reduction in the } \\
\text { numbers of goblet cells). }\end{array}$ & $\begin{array}{l}\text { Granulomas (with giant } \\
\text { cells, without giant cells). }\end{array}$ & \\
\hline 5 & & & $\begin{array}{l}\text { Locations of granulomas } \\
\text { (superficial, deep, } \\
\text { submucosa, serosal). }\end{array}$ & \\
\hline
\end{tabular}

The inflammatory features are defined as an increase of mononuclear inflammatory cells especially lymphoplasmacytic cells in the lamina propria, particularly when localized in its basal thirds, to distinguish CIBD from non CIBD and normal biopsies materials [14, 15]. In addition to the above, all the specimens were examined for any associated dysplasia, the earliest recognizable precursor for the development of colorectal cancer [11].

\section{Results}

In the normal cases the gastrointestinal tract (GIT) appeared as a hollow tube consisting of three layers: mucosa, submucosa, muscularis propria and loose areolar tissue covered by mesothelium where the tract borders on the body cavity (serosa). The examined normal mucosa is lined by flat epithelial surface composed of mucus secreting cells along with goblet cells, parallel straight crypts; homogeneously sized, regular aligned and spaced, less than $10 \%$ of which are branching and whose bottom reaches the muscularis mucosae. The crypts within the mucosa are of uniform length, diameter and spacing. The crypts reach the muscularis mucosae in all areas of the colon except the rectum, where it is normal to have uniform mild shortening (Figure $1 \& 2$ ).

\section{Clinico-endoscopical findings}

All the clinicoendoscopical findings were summarized in Table ( $2 \& 3)$. The study included 100 patients, 60 males and 40 females with ages ranged from 10 years to 60 years (Table 2). Endoscopically, hyperemia of the bowel mucosa found in $20 \%$ of the examined patients, whereas each of erosion, stricture, cobblestone appearance and pseudopolypoidal changes was seen in $10 \%$ of patients, and ulceration found in $15 \%$ of them (Figure 3 ) (Table 3 ).

Majority of the cases were found in children and adults 
with more shift to the age groups which ranged from 21-30 years and more of these cases were seen in males $(60 \%)$. Most of the patients were suffering from abdominal pain associated with diarrhea. In majority of cases diarrhea was associated with mucus and blood, whereas unexplained weight loss was detected in 15 patients.

In (Table 4) most of the received specimens were endoscopical biopsies which were obtained from the rectosigmoid colon and encompassed of $73 \%$ of the specimens. The ileal biopsy was taken from $10 \%$ of patients, whereas ileocecal resection was from 3\%. Grossly all the received resections were formed of an areas of whitish mural indurations with hard whitish mesenteric reactions in conjunction with nodularity and hemorrhages (Figure 4 A\&B).

Histopathological findings:
In concern to crypt architectural abnormalities, branching of the crypts was detected in the majority of cases and observed in $45 \%$ (Figure 5 A \& B), whereas decreased density of the crypts seen in $25 \%$. The inflammatory reactions considered one of the important parameters in the diagnosis of IBD. In this study each of cryptitis and crypt abscess was seen in $20 \%$ of biopsies (Figure 6), and granulomas were in $10 \%$ (Figure 7 ). In the same theme combined inflammatory reactions including mucosal superficial erosions (Figure 8), and transmural inflammations (Figure 9) were detected in 30\% of cases. Regarding the precancerous associated dysplasia, it was seen in $6 \%$ of cases, one of them is of low grade type, whereas the other 5 are of high-grade type (Figure 8), while colon carcinoma was found in one case and it located in rectosigmoid region (Figure 10).

Table 2. Clinical features of all cases studied.

\begin{tabular}{lllll}
\hline Sex & \multirow{2}{*}{ Age } & \multirow{2}{*}{ of case } & & Clinical manifestations \\
\cline { 1 - 3 } Males & Females & & Symptoms & \# of cases \\
\hline & $10-20$ & 20 & Abdominal pain & 20 \\
60 & $21-30$ & 50 & Pain \& diarrhea & 30 \\
& $31-40$ & 10 & Bloody diarrhea & 20 \\
& $41-50$ & 15 & Anemia & 15 \\
Total No. of cases & $51-60$ & 5 & Unexplained \& weight loss & 15 \\
\hline
\end{tabular}

Table 3. Endoscopical findings of all patients

\begin{tabular}{ll}
\hline Endoscopical manifestations & Number of cases \\
\hline Hyperemic mucosa & 20 \\
Erosions & 10 \\
Ulcerations & 15 \\
Strictures & 10 \\
Cobblestone appearance & 10 \\
Mucosal granularity and friability & 16 \\
Discontinuous (skip) lesions & 9 \\
Pseudopolyps & 10 \\
Total No. of cases & 100 \\
\hline
\end{tabular}

Table 4. Anatomical locations and biopsy sites from all studied patients with IBD and normal subjects:

\begin{tabular}{ll}
\hline Site & Number of patients \\
\hline Rectosigmoid biopsies & 73 \\
Ileal biopsies & 10 \\
Ileocecal resections specimens & 3 \\
Duodenal biopsies & 6 \\
Biopsies from duodenum, stomach and esophagus & 3 \\
Biopsy from ileum and colon & 5 \\
Total No. of cases & 100 \\
\hline
\end{tabular}

Table 5. Histopathological findings of all studied cases.

\begin{tabular}{|c|c|c|c|c|c|c|c|}
\hline Crypt abnormalities & No. of cases & Mucosal-epithelial changes & No. of cases & Inflammation & No. of cases & Associations & No. of cases \\
\hline Branching & 45 & Intact mucosa & 25 & Transmural & 20 & Dysplasia & 6 \\
\hline Shortening & 10 & Erosions & 50 & Cryptitis & 20 & Cancer & 1 \\
\hline$\downarrow$ density & 25 & Ulcerations & 10 & Crypt abscess & 20 & & \\
\hline Branching with $\downarrow$ density & 20 & Mucin depletion & 15 & $\begin{array}{l}\text { Granulomas } \\
\text { Combined }\end{array}$ & $\begin{array}{l}10 \\
30\end{array}$ & & \\
\hline Total No. of cases & 100 & & 100 & 100 & & & \\
\hline
\end{tabular}




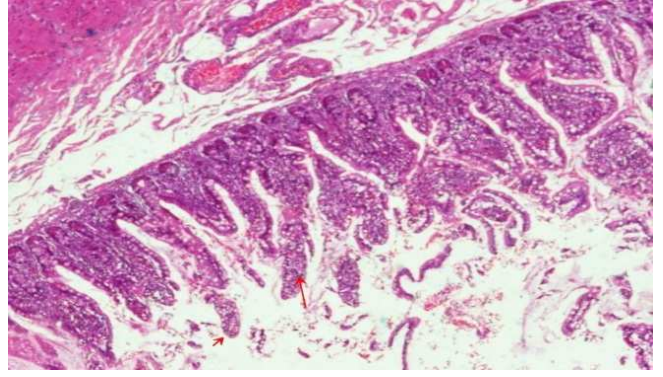

Figure 1. Section in normal small bowel mucosa revealing projecting villi (arrows) with secreting columnar lining and goblet cells (H\&E, X40).

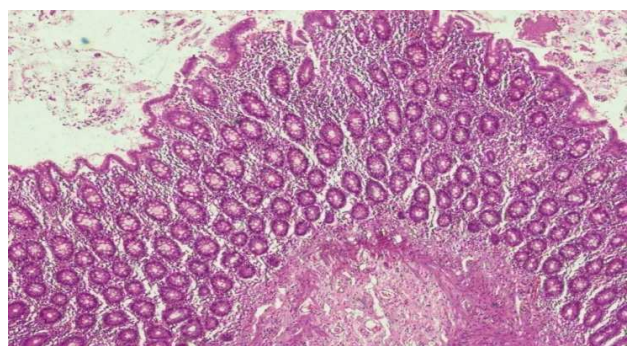

Figure 2. Cross section in normal colonic mucosa showing normal crypt architecture with intact surface epithelium, (H\& E, X40).



Figure 3. Endoscopic features of examined colon in 22-years-old patient showing pseudopolyps (thick arrow) with an ulceration area (thin arrow).


Figure $4(\boldsymbol{A} \& \boldsymbol{B}) . A$ case of $C D$ in 18 years male patient with ileocecal resection revealing whitish mural thickening with induration of the wall $(A$ short arrow) and mesenteric nodularity with fat hemorrhages (B long arrow).
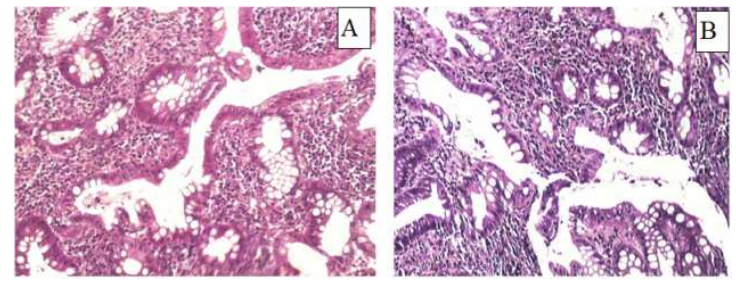

Figure $5(\boldsymbol{A} \boldsymbol{\&} \boldsymbol{B})$. Ulcerative colitis showing crypt abnormalities with branching, decreased density and increased lamina propria inflammatory cells $(H \&$ E, X100).

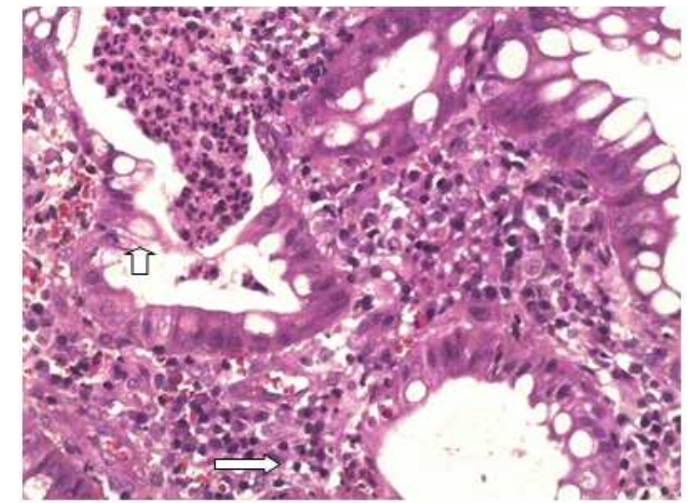

Figure 6. A case of UC revealing crypitis (long arrow) and crypt abscess formation (short arrow) in conjunction with an increase of mononuclear inflammation (H\&E, X100).



Figure 7. A case of $C D$ from ileocecal resection specimen revealing non caseating-sarcoid granuloma in association with surface ulcerations and an increased mononuclear inflammation ( $H \& E, X 100)$.

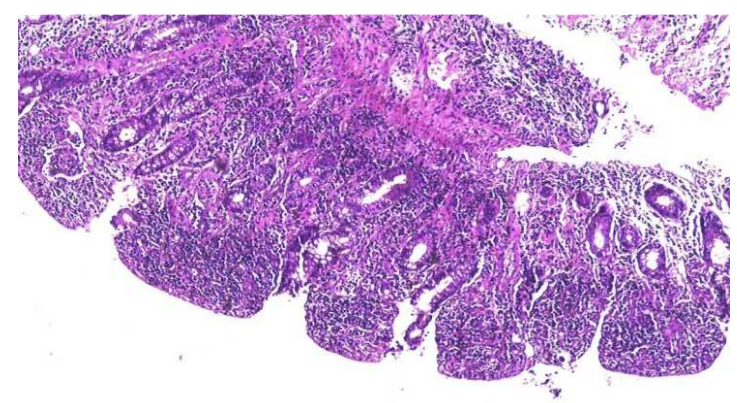

Figure 8. A case of $C D$ affecting ileum showing combined severe transmural inflammation along with superficial and deep ulcerations (H\& E, X100).
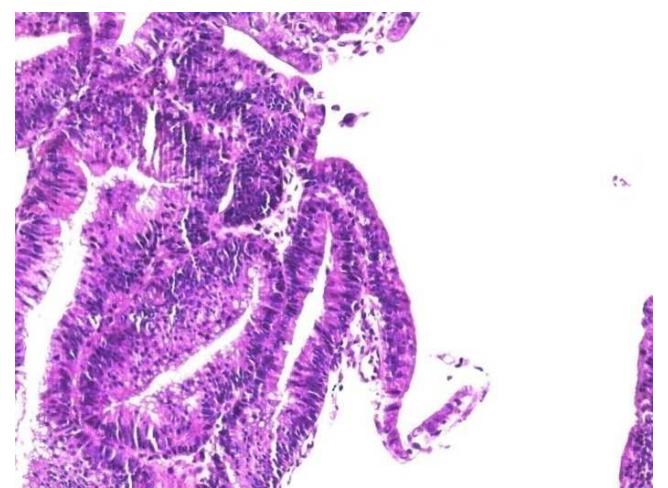

Figure 9. A case of UC showing an associated high grade dysplasia of the colonic epithelia (H\&E, X200). 


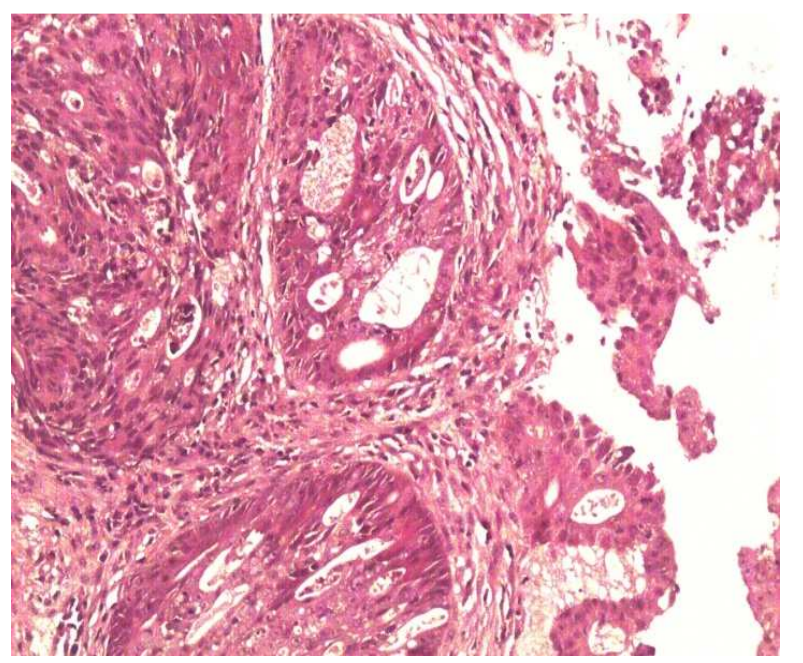

Figure 10. A case of colonic adenocarcinoma showing cribriform features with severe dysplasia in top of UC (H\&E, X200).

\section{Discussion}

Colonoscopic biopsies are an essential step in the diagnostic work-up of patients with IBD. There are no single pathognomonic lesion has been identified to date for the most common forms of colitis, the diagnosis usually derives from a complex evaluation of multiple microscopic changes and their topographical distribution [16, 17]. Also, the diagnostic accuracy of IBD has been demonstrated to increase with the number of obtained biopsies. Therefore, it is mandatory to perform an extensive bioptic sampling, especially in the case of newly diagnosed IBD [18, 19].

In the present study the mucosal architecture abnormalities well apparent in the form of mucosal-epithelial surface changes in which loss of the typical flat profile, showing erosions or even a pseudovillous change. Another changes in the form of crypt distortion as irregular branching, and decrease in the density of crypts with increasing distance between the bottom of the crypts and the muscularis mucosae, these results in agreement with [5, 19].

The present study showed reduction in the number of goblet cells and/or in their mucus content either in the crypts or in the surface epithelium which were in agreement with [5, 19].

Regarding age groups majority of the cases seen among this study were under 30 years and were males. A study done by [20] reported that IBD is an important cause of GIT troubles in children and adolescents, and 10-20\% of cases were diagnosed before the age of 18 years. In the same theme the epidemiology of inflammatory bowel diseases (IBD) has been well studied in adults, UC has an early onset; children could be at high risk of disease complications, surgery, and develop extra-intestinal manifestations [21].

Inflammation is considered one of the important distinguishing feature between IBD, normal subjects and non specific types of colitis and also can specify the duration of IBD. Inflammation was detected in $90 \%$ of cases, and with blind diagnosis and evaluation of IBD, it was seen in $>50 \%$ of patients compared to normal biopsies [13, 22]. A study mentioned the best variables of predicting uncomplicated IBD are lamina propria lymphocytes (and eosinophils) with absence of lymphocytic infiltration of the epithelium [23]. In this study inflammatory reactions seen in almost all cases, among them each of transmural inflammation, cryptitis and crypt abscess formations found in $20 \%$, whereas non sarcoid like epithelioid granulomas identified in $10 \%$ of cases. These findings are in near to results obtained by [5, 24]. The European consensus (2013) reported the features which are highly predictive of UC are including villous irregular architecture, crypt distortion as branching, inflammation and cryptitis [16]. In addition to the above, plasmacytosis particularly in the base of the crypts is still an important diagnostic feature of IBD from non-IBD colitis and is common in both UC $(63 \%)$, as well as in CD $(62 \%)[4,13]$.

Transmural inflammation and granulomas are typical discriminating features for a diagnosis of $\mathrm{CD}$ as opposed to other conditions, particularly UC in both endoscopic biopsies and resection specimens [25]. In this study granulomas were observed in $10 \%$ and majority located in the submucosa, whereas in the resection cases were seen widely and extending to the mesentery. European consensus (2013) discussed the diagnostic features of CD included granulomas, crypt architectural abnormalities, in conjunction to inflammation [16]. An international workshop on the initial hisopathological diagnosis of colitis reported that $64 \%$ of cases were $\mathrm{CD}$, and $74 \%$ were UC [18]. In addition to the above various histopathological features were mentioned to differentiate CIBD from non CIBD and also to discriminate $\mathrm{UC}$ from $\mathrm{CD}$, among them a study used mentioned 16 features were significant, among them 3 discriminating features including an increase of lymphocytes, plasma cells in the lamina propria, branching of crypts, and cryptitis can diagnose UC in $89 \%$ of cases, whereas 3 others consider the best discriminating histopathological features of $\mathrm{CD}$ that were including mucosal surface aspect irregularities, epithelioid granuloma, and an excess of histiocytes (Seldenrijk 1991).Many reviewers were considering granuloma to be very specific, but not very sensitive feature for diagnosis of CD [18, 26]. Also, Bentley et al. 2002 [18] reported these histopathological features were better confirmed by multiple endoscopic biopsies rather than single rectal biopsy. This is consistent with the pathological nature of CD. In the same theme the presence of diffuse transmural inflammation in single biopsy or sequential colonic biopsies was found to discriminate CD from UC [27].

The used selected histopathological features in this study have been mentioned and reported in other authors with near similarities, as [28, 29] found crypt architectural irregularities, an increase of lymphocytes and plasma cells infiltrates, and cryptits were diagnostic of IBD over non IBD colitis.

It is known that the most lethal long term complication of IBD is colorectal cancer (CRC), the risk of its development significantly increases in the patients of IBD. Patients with $\mathrm{UC}$ and $\mathrm{CD}$ bear an about 10- and 4-fold increased risk, respectively $[1,30,31]$. 


\section{Conclusion}

This study concluded that diagnosis of IBD needs interdepartmental correlations to avoid under- or overdiagnosis. As well as the accurate discrimination of CIBD from non CIBD forms is a backbone for therapeutic and prognostic strategies.

\section{Acknowledgments}

The authors thank all our colleges in particular Dr. Khalid Al-Hamad Consultant endoscopic surgeon as well as staff members of Pathology Department especially Miss Nijjara and Nasemol, Arar Central Hospital, Saudi Arabia for their kind help during the preparation of this study.

\section{References}

[1] Tanaka T (2009): Colorectal carcinogenesis: Review of human and experimental animal studies. J Carcinog; 8:5.

[2] Burisch J, Jess T, Martinato M and Lakatos PL (2013): The burden of inflammatory bowel disease in Europe. J Crohns Colitis; 7:322-37.

[3] $\mathrm{Ng} \mathrm{SC}$, Bernstein CN, Vatn MH, Lakatos PL, Loftus EV, Jr., Tysk C, O'Morain C, Moum B and Colombel JF (2013): Geographical variability and environmental risk factors in inflammatory bowel disease. Gut, 62:630-49.

[4] Schumacher G, Kollberg B, and Sandstedt B (1994): A prospective study of first attacks of inflammatory bowel disease and infectious colitis.Histologic course during the 1st year after presentation. Scand J Gastroenterol; 29:318-332.

[5] Jenkins D, Balsitis M, Gallivan S, Dixon MF, Gilmour HM, Shepherd NA, Theodossi A, and Williams GT (1997): Guidelines for the initial biopsy diagnosis of suspected chronic idiopathic inflammatory bowel disease. The British Society of Gastro-enterology Initiative. J Clin Pathol; 50: 93105.

[6] Bernstein CN, Nugent Z, Longobardi T, and Blanchard JF (2009): Isotretinoin is not associated with inflammatory bowel disease: a population-based case-control study. Am J Gastroenterol. Nov; 104(11):2774-8.

[7] Cornaggia M, Leutner M, Mescoli C, Sturniolo GC, and Gullotta R (2011): Chronic idiopathic inflammatory bowel diseases: the histology report. Dig Liver Dis.; 43 Suppl 4:293303.

[8] Russell RK, and Satsangi J (2004). IBD: A Family Affair. Best Pract Res Clin Gastroenterol; Jun; 18(3):525-39

[9] Noomen CG, Hommes DW, and Fidder HH, (2009): Update on genetics in infammatory disease. Best Pract Res Clin Gastroenterol; 23(2):233-243.

[10] Van AG, Axel D, Bernd B, Silvio D, Paolo G, Gabriele M, Laurent B et al. (2013): The second European evidencebased consensus on the diagnosis and management of Ulcerative Colitis Part 3: special situations. Journal of Crohn's\& Colitis, February; 7(1):1-33

[11] Harpaz N, and Polydorides A D (2010): Colorectal Dysplasia in Chronic Inflammatory Bowel Disease Pathology, Clinical Implications, and Pathogenesis. Arch Pathol Lab Med.; $134: 876-895$

[12] Villanacci V, Antonelli E, Geboes K, Casella G, and Bassotti G, (2013): Histological healing in inflammatory bowel disease: A still unfulfilled promise. World J Gastroenterol; 19(7): 968978.

[13] Seldenrijk CA, Morson BC, Meuwissen SG, Schipper NW, Lindeman J, and Meijer CJ (1991): Histopathological evaluation of colonic mucosal biopsy specimens in chronic inflammatory bowel disease: diagnostic implications. Gut; 32: 1514-1520.

[14] Scott BB, Goodall A, Stephenson P, and Jenkins D (1983): Rectal mucosal plasma cells in inflammatory bowel disease. Gut; 24: 519-524.

[15] Rubio CA, Johansson C, Uribe A, and KockY (1984): A quantitative method of estimating inflammation in the rectal mucosa. IV. Ulcerative colitis in remission. Scand $\mathrm{J}$ Gastroenterol; 19: 525-530.

[16] Margo F, Langner C, Driessen A, Ensari A, Geboes K, Mantzaris GJ, Villanacci V, Becheanu G, BorralhoNunes, Cathomas G, Fries W, et al. (2013): European consensus on the histopathology of inflammatory bowel disease. Journal of Crohn's and Colitis; 7, 827-851.

[17] Hoffmann JC, Preiss JC, Autschbach F, et al. (2008): Clinical practice guideline on diagnosis and treatment of Crohn's disease. Z Gastroenterol; 46:1094-146.

[18] Bentley E, Jenkins D, Campbell F, and Warren B (2002): How could pathologists improve the initial diagnosis of colitis? Evidence from an international workshop. J Clin Pathol; 55:955-60.

[19] Geboes K, Colombel JF, Greenstein A, A, Jewell DP, Sandborn WJ, Vatn MH, and Warren B (2008): Indeterminate Colitis: A Review of the Concept - What's in a Name? Inflamm Bowel Dis.; 14:850-57.

[20] Kugathasan S, Judd RH, Hoffmann RG, HeikenenJ, Telega G, Khan F, et al (2003): Epidemiologic and clinical characteristics of children with newly diagnosed inflammatory bowel disease in Wisconsin: a statewide population based study. J Pediatr; 143:525-31.

[21] Malaty HM, Bincy PA, Mehta S, Garnett EA, and Ferry FD (2013): The natural history of ulcerative colitis in a pediatric population: a follow-up population-based cohort study. Clin Exp Gastroenterol. 2013; 6: 77-83.

[22] Jenkins D, Goodall A, Drew K, and Scott BB (1988): What is colitis? Statistical approach to distinguishing clinically important inflammatory change in rectal biopsy specimens. J ClinPathol; 41: 72-79.

[23] Bataille F, Klebl F, Rummele P, Straub RH, Wild P, Schölmerich J, and Hofstädter F (2003): Histopathological parameters as predictors for the course of Crohn's disease. Virchows Arch; 443:501-7.

[24] Geboes K (2003). Histopathology of Crohn's Disease and Ulcerative Colitis. IBD 4th ed. 18. New York: ChurchillLivingstone; (255-275).

[25] Swan NC, Geoghegan JG, O'Donoghue DP, Hyland JM, and Sheahan K (1994): Fulminant colitis in inflammatory bowel disease: detailed pathologic and clinical analysis. Dis Colon Rectum; 41: 1511-5. 
[26] Tobin JM, Sinha B, Ramani P, Saleh AR, and Murphy MS (2001): Upper gastrointestinal mucosal disease in pediatric Crohn's disease and ulcerative colitis: a blinded, controlled study. J Pediatr Gastroenterol Nutr; 32:443-8.

[27] Konuma Y, Tanaka M, Saito H, Munakata A, Yoshida Y (1995): A study of the histological criteria for ulcerative colitis retrospective evaluation of multiple colonic biopsies. J Gastroenterol; 30:189-94.

[28] Berre NL, Heresbach D, Kerbaol M, Caulet S, Bretagne JF, Chaperon J, Gosselin M, and Ramee MP,(1995): Histological discrimination of idiopathic inflammatory bowel disease from other types of colitis. J Clin Pathol; 48:749-753.
[29] Surawicz CM, Haggit RC, Husseman M, McFarland LV, (1994): Mucosal biopsy diagnosis of colitis: acute self-limited colitis and idiopathic inflammatory bowel disease. Gastroenterology; 107:755-63.

[30] Yano Y, Matsui T, Hirai F, Okado Y, Sato Y, Tsurumi K, Ishikawa S, Beppu T, Koga A, Yoshizawa N, Higashi D and Futami K (2013): Cancer risk in Japanese Crohn's disease patients: Investigation of the standardized incidence ratio. $\mathrm{J}$ Gastroenterol Hepatol 2013.

[31] Raithel M, Weidenhiller M, Schwab D, Muller S and Hahn EG (2001): Pathobiology of dysplasia in chronic inflammatory bowel disease: Current recommendations for surveillance of dysplasia. Z Gastroenterol, 39:861-75. 